Article

\title{
Analysis of L-Band SAR Data for Soil Moisture Estimations over Agricultural Areas in the Tropics
}

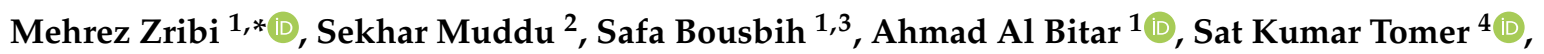 \\ Nicolas Baghdadi ${ }^{5}$ and Soumya Bandyopadhyay ${ }^{6}$ \\ 1 CESBIO, Université de Toulouse, CNRS/UPS/IRD/CNES, 18 av. Edouard Belin, bpi 2801, CEDEX 9, \\ 31401 Toulouse, France; safabousbih1@outlook.fr (S.B.); ahmad.albitar@cesbio.cnes.fr (A.A.B.) \\ 2 Department of Civil Engineering \& Indo-French Cell for Water Sciences, Indian Institute of Science, \\ Bangalore 560012, India; sekhar.muddu@gmail.com \\ 3 Université de Carthage/INAT/LR GREEN-TEAM, 43 Avenue Charles Nicolle, Tunis 1082, Tunisia \\ 4 Satyukt Analytics Pvt Ltd., Bangalore 560094, India; satkumartomer@gmail.com \\ 5 IRSTEA, TETIS, University of Montpellier, 500 rue François Breton, CEDEX 5, 34093 Montpellier, France; \\ nicolas.baghdadi@teledetection.fr \\ 6 RRSC-East, NRSC, Indian Space Research Organisation (ISRO), Kolkata 700156, India; \\ sbanerjee377@gmail.com \\ * Correspondence: mehrez.zribi@ird.fr; Tel.: +(33)-5-6155-8525
}

Received: 26 February 2019; Accepted: 7 May 2019; Published: 11 May 2019

check for updates

\begin{abstract}
The main objective of this study is to analyze the potential use of L-band radar data for the estimation of soil moisture over tropical agricultural areas under dense vegetation cover conditions. Ten radar images were acquired using the Phased Array Synthetic Aperture Radar/Advanced Land Observing Satellite (PALSAR/ALOS)-2 sensor over the Berambadi watershed (south India), between June and October of 2018. Simultaneous ground measurements of soil moisture, soil roughness, and leaf area index (LAI) were also recorded. The sensitivity of PALSAR observations to variations in soil moisture has been reported by several authors, and is confirmed in the present study, even for the case of very dense crops. The radar signals are simulated using five different radar backscattering models (physical and semi-empirical), over bare soil, and over areas with various types of crop cover (turmeric, marigold, and sorghum). When the semi-empirical water cloud model (WCM) is parameterized as a function of the LAI, to account for the vegetation's contribution to the backscattered signal, it can provide relatively accurate estimations of soil moisture in turmeric and marigold fields, but has certain limitations when applied to sorghum fields. Observed limitations highlight the need to expand the analysis beyond the LAI by including additional vegetation parameters in order to take into account volume scattering in the L-band backscattered radar signal for accurate soil moisture estimation.
\end{abstract}

Keywords: PALSAR/ALOS-2; SAR; L-band; soil; moisture; roughness; vegetation; water cloud model; backscattering model

\section{Introduction}

An accurate knowledge of soil moisture is important for the evaluation of several processes, such as evapotranspiration, infiltration, and runoff, and for the modeling of the soil-vegetation-atmosphere interface [1-5]. In an agricultural context, soil moisture measurements can contribute to the management of water resources [6,7]. Although soil moisture has long been measured through the use of local field measurements, this technique can become impractical and very costly when extended surface areas need to be measured and/or long-term monitoring is required. Over the last 30 years, various algorithms based on the use of optical and radar remote sensing observations have been proposed for the estimation of soil moisture [8-11]. Currently, various global soil moisture products are available 
on an operational basis. These rely on microwave radiometric measurements (e.g., SMOS: Soil Moisture and Ocean Salinity, AMSR-E: Advanced Microwave Scanning Radiometer for EOS, SMAP: Soil Moisture Active and Passive mission) and/or scatterometer measurements (e.g., ASCAT: Advanced SCATterometer), and have a spatial resolution ranging between 10 and $40 \mathrm{~km} \mathrm{[12-16].} \mathrm{As} \mathrm{agricultural}$ farms are small in size $(\sim$ ha), these global soil moisture products alone are of little use for the evaluation of soil moisture at the scale of individual fields.

Optical/thermal and synthetic aperture radar (SAR) sensors can generate high spatial resolution (less than $30 \mathrm{~m}$ ) images, which can be processed to provide meaningful information for agricultural farms. On the other hand, optical and thermal sensors have a reduced sensitivity to the soil underneath the vegetation biomass, and are unable to penetrate clouds, thus limiting their relevance for the study of tropical agriculture [17]. High resolution SAR data has been used in several studies for the estimation of soil moisture [18-23], and in the last decade several new satellites have been launched, with SAR payloads operating in the $\mathrm{C}$ - and X-bands (ASAR/ENVISAT, RADARSAT-1,2, TerraSAR-X, COSMO-SKYMED, RISAT-1, and the Sentinel-1 constellation). The recent availability of these data have led to the development of new algorithms, such as the multi-temporal [18], neural networks [19,20], cumulative density function (CDF) transformation [21], and change detection algorithms [22], and has enabled the direct inversion of physical or empirical models [23].

In the case of a bare soil surface, the backscattered radar signal is affected by the dielectric constant of the first few centimeters of the upper surface layer, and by the soil roughness. In practice, the penetration depth of the radar signal varies between $1 \mathrm{~cm}$ in the X-band, and $5 \mathrm{~cm}$ in the L-band, in the case of high soil moisture $[10,24]$. The dielectric constant of the soil depends on its moisture and texture, and the frequency band used by the radar sensor [25]. Several studies have quantified radar signal backscattering as a function of soil moisture and roughness [26]. The backscattering coefficient is found to have a relatively high sensitivity to soil moisture at lower incidence angles $\left(20^{\circ}-35^{\circ}\right)[27,28]$. In this context, various radar backscattering models (physical, semi-empirical, and empirical) have been developed in an effort to improve scientific understanding of the relationship between the backscattering coefficient and the parameters used to characterize the soil. The most frequently used models are the integral equation model (IEM) proposed by Fung et al. [29], and the advanced integrated equation model (AIEM) [30], both of which can be applied to a large range of soil roughness conditions. Semi-empirical models, such as those of Oh [31], Dubois [32], and Baghdadi [33], have been proposed and have the advantage of providing simple analytical relationships between the backscattered radar signal and the physical soil parameters.

When the surface is covered with vegetation, the backscattered radar signal depends not only on the soil, but also on the characteristics of the vegetation. Several studies have been proposed, based on solving of the radiative transfer equation, to account for the contribution to the total radar backscattering coefficient produced by the vegetation cover [34,35]. A semi-empirical approach, known as the water cloud model [35], has been widely used in the literature due to its simplicity. This model considers the total backscattered radar signal to be the sum of contributions from the vegetation cover, together with a second contributor related to the soil, which is attenuated by the vegetation cover. The attenuation produced by the vegetation has been estimated using physical, crop-related variables such as the biomass, vegetation water content, crop height, and leaf area index (LAI) [36-38], and through the use of satellite observations of optical indices such as the Normalized Difference Vegetation Index (NDVI) [39].

These studies have led to an improved understanding of radar scattering over agricultural surfaces in the C-and X-bands. Different algorithms have been proposed, in particular for the estimation of soil moisture, for experimental as well as operational applications using Sentinel-1 data [20,22,40,41].

In this context, although L-band radars are particularly effective in terms of their ability to penetrate the vegetation cover, for the estimation of underlying soil parameters, relatively small volumes of remotely sensed data have been produced in this frequency band. In practice, recent spaceborne L-band measurements are limited to those provided by two JAXA missions: (PALSAR/ALOS) [42] and 
PALSAR/ALOS-2 [43], to SMAP measurements recorded during a short period in 2015 [44], and to scatterometer data provided by the Aquarius Sea Surface Salinity mission. The L-band is particularly suitable for observations in tropical areas characterized by a dense vegetation cover and the frequent presence of dense clouds, which can lead to strong attenuation even in C-band radar data [45]. Various studies have analyzed the potential of airborne or spaceborne L-band radar for the observation of agricultural surfaces, as well as for the estimation of land cover and vegetation properties [46-50]. Several studies have proposed the use of polarimetric airborne SAR measurements to analyze soil moisture [51-63], and have demonstrated the potential of L-band data for the high accuracy retrieval of soil moisture. These studies applied polarimetric decomposition models to the analysis of different types of vegetation cover (corn, soybean, wheat, etc.). Jagdhuber et al. [51] reported an accuracy of 6-8 vol.\% using a multi-angular polarimetric decomposition, applied to a variety of crop types, Wang et al. [59] tested various polarimetric decompositions for the retrieval of soil moisture over different areas characterized by a vegetation cover, with a root mean square error (RMSE) of 6-11 vol.\%. Using Aquarius data, Liu et al. [63] proposed a method for the global estimation of soil moisture. Using the water cloud model, they obtained an accuracy of 6 vol.\%, when comparing Aquarius moisture estimations with passive microwave radiometer products. In the case of future L-band remote-sensing missions such as NISAR ISRO/NASA [64], further progress is needed in the understanding of radar signals, in order to progress towards the development of more operational algorithms, in particular those based on the use of one or two polarization configurations.

In this context, the aim of the present study is to discuss the potential use of L-band radar data for the estimation of soil moisture over agricultural tropical areas. Section 2 describes the study site, satellite images, and ground measurement database. Section 3 presents methodologies and models considered in the proposed study. Section 4 provides a statistical analysis of the relationships established between the backscattered radar signals and soil moisture. We present the performance of different models for the simulation of backscattering over bare and vegetation-covered soils and finally, we discuss the potential of WCM inversion for soil moisture estimations. Our conclusions are provided in Section 5.

\section{Study Site and Dataset Description}

\subsection{Description of the Study Site}

The study was carried out in the Berambadi watershed (Figure 1), located near to the town of Gundlupet, with the Bandipur National park lying at its western boundary, in the Chamarajanagar district of Karnataka state, South India (centered at approximately $11.75^{\circ} \mathrm{N}, 76.6^{\circ} \mathrm{E}$ ) [21]. The Berambadi watershed lies in a semi-arid climate zone, classified as AWh (equatorial, desert/arid, dry) according to the latest Köppen-Geiger world climate classification [65]. It has a mean annual, dominantly South-West monsoon rainfall of $800 \mathrm{~mm}$. It is included within the French environmental observatory BVET [66] and the so-called: "Assimilation of Multi-satellite data at Berambadi watershed for Hydrology And land Surface" experiment (AMBHAS) [67]. The soil texture map provided by the Karnataka State Remote Sensing Application Centre (KSRSAC) reveals the significant spatial variability of soil textures in this area, with sandy clay, clay, sandy clay loam, clay loam, sandy loam, and loamy sand soil types [21]. During kharif (summer) and rabi (winter), marigold, sorghum, turmeric, sunflower, maize, finger millet, vegetables, lentils, groundnut, etc., are grown. As the climate is semi-arid, irrigation is commonly used in kharif (to complement insufficient monsoon rains), very frequently in rabi and always in summer [68]. This area is characterized by small agricultural plots, with a median surface area of less than 0.3 hectares. 


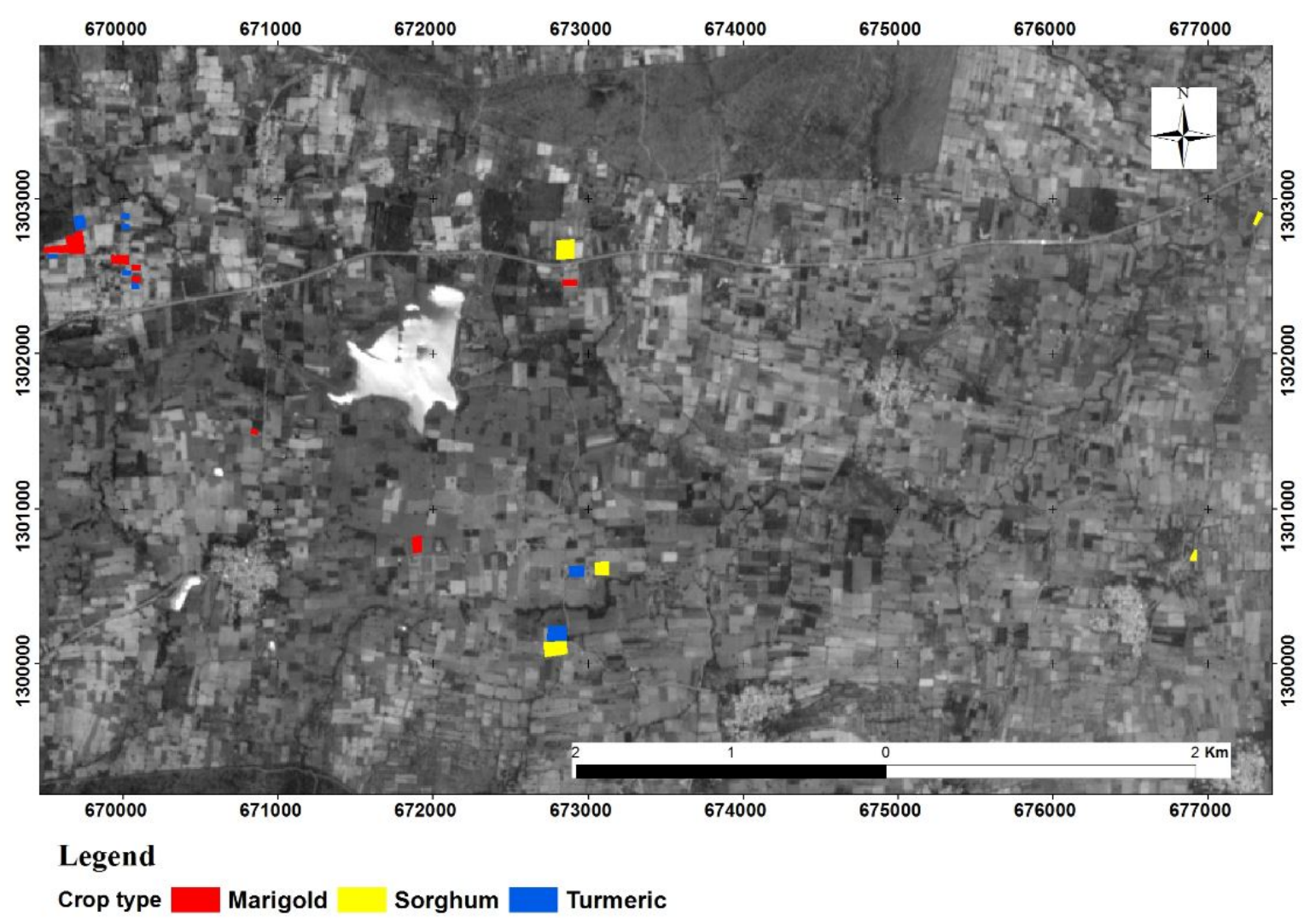

Figure 1. View of the Berambadi watershed, showing the location of studied plots of marigold, sorghum, and turmeric.

\subsection{Dataset Description}

\subsubsection{SAR Data}

Ten L-band (wavelength $\sim 24 \mathrm{~cm}$ in free space) SAR images acquired by the Phased Array Synthetic Aperture Radar (PALSAR), the main payload of ALOS-2 (Advanced Land Observing Satellite), were analyzed for the present study. These images were recorded in the dual-polarization mode, with $\mathrm{HH}$ (horizontal-horizontal) and HV (horizontal-vertical) polarizations at a pixel size of $6 \times 6 \mathrm{~m}$. The SAR images were firstly multi-looked to reduce speckle, using the NEST software [69]. We considered two looks in the azimuthal direction and one in the range direction. The images were then radiometrically calibrated to derive the backscattering coefficients $\sigma_{0}$. As NEST is unable to perform automatic geo-referencing of ALOS-2 images, this step is carried out using control points retrieved from a Sentinel-2 optical image of the site. All of the images were geo-referenced and superimposed, with a root mean square (RMS) control point error of approximately one pixel. The mean backscattering coefficient (linear scale) was computed from each calibrated SAR image, by averaging the values of $\sigma_{0}$ for all pixels corresponding to the reference plots of interest.

\subsubsection{Ground Measurements}

During the five-month period from June-October 2018, field measurements were recorded at the same time as the PALSAR radar acquisitions, which have a revisit cycle of 14 days. At the Berambadi site, this period corresponds to the Southwest Indian monsoon, which is accompanied by high levels of precipitation and the growth of vegetation. In this area, the agricultural cycle commences in May-June.

Three major crops were used in the analysis. These comprised of 16 plots of marigold, 6 plots of turmeric, and 7 plots of sorghum, as shown in Figure 2. The agricultural cycle of turmeric extends from May until December, whereas marigold and sorghum are sown in May and harvested in August. 
Depending on each farmer's strategy, slightly different agricultural cycles can be implemented with the same crop in different plots. For this reason, peak vegetation growth may not necessarily occur at the same time for all plots containing the same crop. All irrigated fields directly use groundwater on their fields or temporarily store it in individual farm ponds.

Most ground measurements were made before mid-August, prior to the harvesting of marigold and sorghum. This allows to monitor the entire agricultural cycle for these two crops. In the case of turmeric, the field campaigns were extended to mid-September. These measurements are sufficient to consider almost all the phenological cycle of the vegetation and the associated variations of soil moisture. In view of the $6 \times 6 \mathrm{~m}$ pixels recorded by PALSAR, sufficiently large reference fields were selected (at least 0.5 ha in the case of the present study), to enhance the accuracy of the mean radar signal computed for each field.

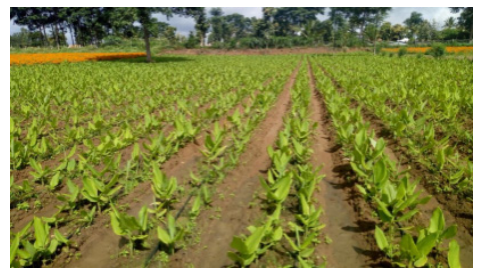

(a)

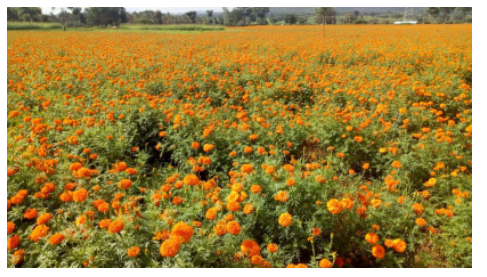

(b)

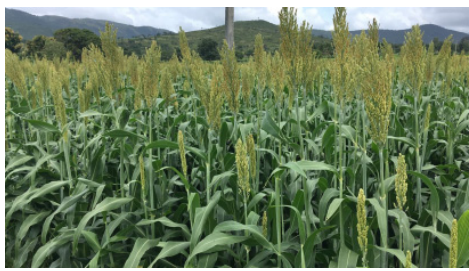

(c)

Figure 2. Illustration of three agricultural fields: (a) turmeric, (b) marigold, (c) sorghum.

Soil moisture and leaf area index measurements were recorded on each reference plot, at approximately the same time as each radar acquisition. The roughness observations were made at the beginning of the ground campaign for a selected number of reference plots.

\section{Soil Moisture Measurements}

Soil moisture measurements were performed using a handheld theta probe (SM-300, Delta-T devices, Ltd, Cambridge, UK), which measures the mean value of soil moisture down to a depth of $5 \mathrm{~cm}$. Local calibration of the probe was achieved with 76 gravimetric measurements, confirming its good performance, with a correlation coefficient of 0.91 and a RMSE of $0.031 \mathrm{~m}^{3} / \mathrm{m}^{3}$ [21]. Three samples were taken in each reference plot, at the same time (within an interval of two hours) as the overhead pass of the PALSAR-2 satellite. The soil moisture determined for each field was thus computed from the mean value of these measurements. During the measurement campaigns the values of volumetric soil moisture ranged between $2 \%$ and $57 \%$ in reference fields. As shown in Figure 3 , for the three crops (turmeric, marigold, sorghum), the highest moisture mean levels are observed in July. On each of the seven different measurement dates the soil moisture varies greatly with a higher standard deviation for marigold and sorghum crops compared to turmeric. This is due to differences in moisture level between irrigated and rainfed fields. 


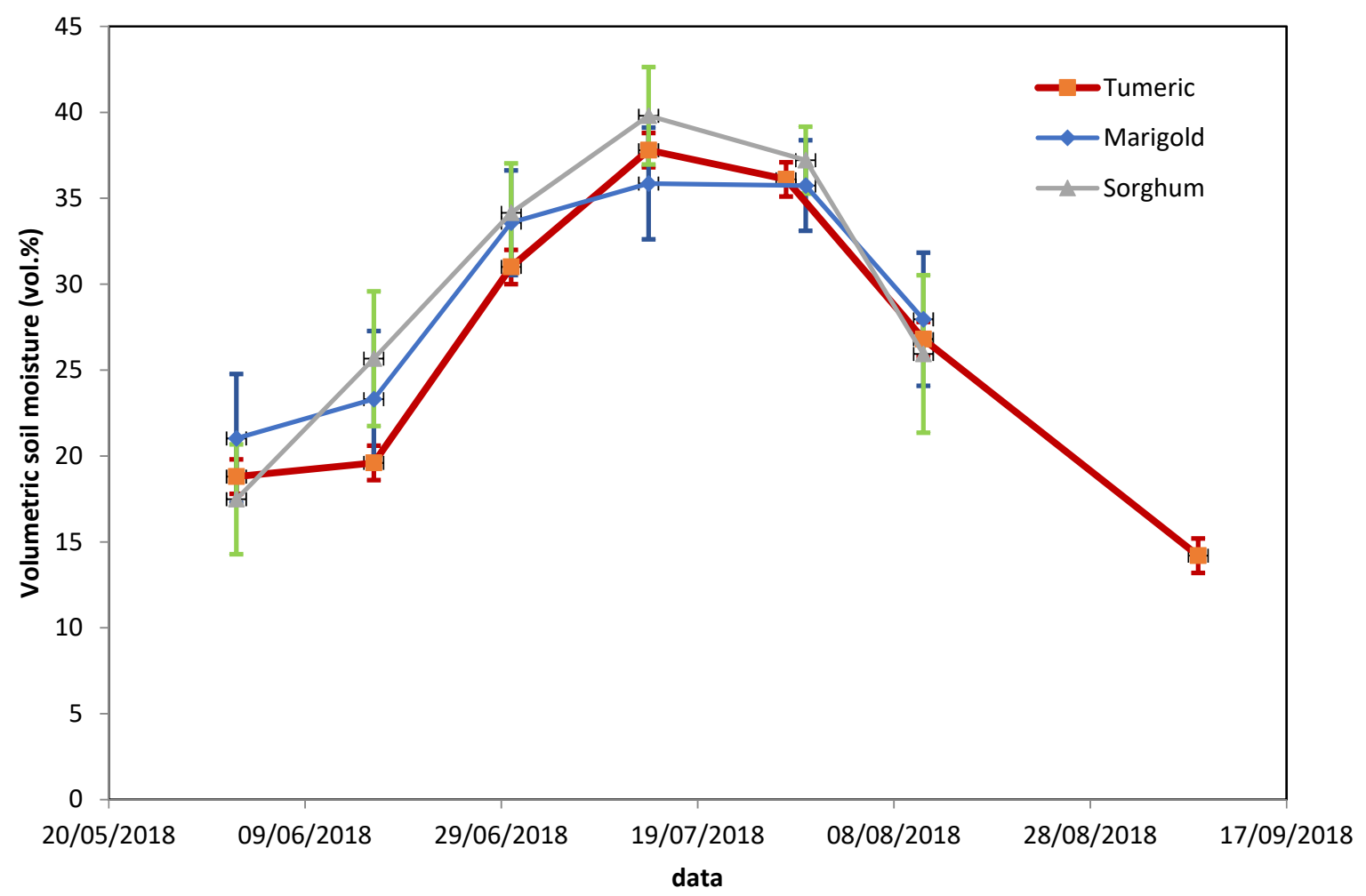

Figure 3. In situ soil moisture measurements in reference fields during the ground campaigns.

Leaf Area Index Measurements

The leaf area index (LAI) is defined as the total, one-sided area of leaf tissue per unit ground surface area, and is thus a dimensionless quantity characterizing the vegetation cover of an ecosystem. During the ground campaigns, the LAI was derived using the LAI-2200C Plant Canopy Analyzer. Three measurements were made in each reference field, at approximately the same time as the satellite acquisitions. During the campaigns organized for the present study of reference fields, the LAI ranged between approximately 0 and 5 for the three crops of interest (turmeric, marigold and sorghum). As shown in Figure 4, the average LAI value on the turmeric fields increase over the seven measurement dates, whereas for the sorghum or marigold, the LAI decreases on the last date with the end of their agricultural cycle (mid-august). The LAI varies considerably from one field to another, even for measurements of the same crop made on the same date, as shown in Figure 4. This result is characteristic of tropical areas, where farmers often have different agricultural strategies in terms of planting dates, which makes it difficult to identify clear trends for marigold and sorghum, contrary to the case of agricultural regions in Europe [70]. 


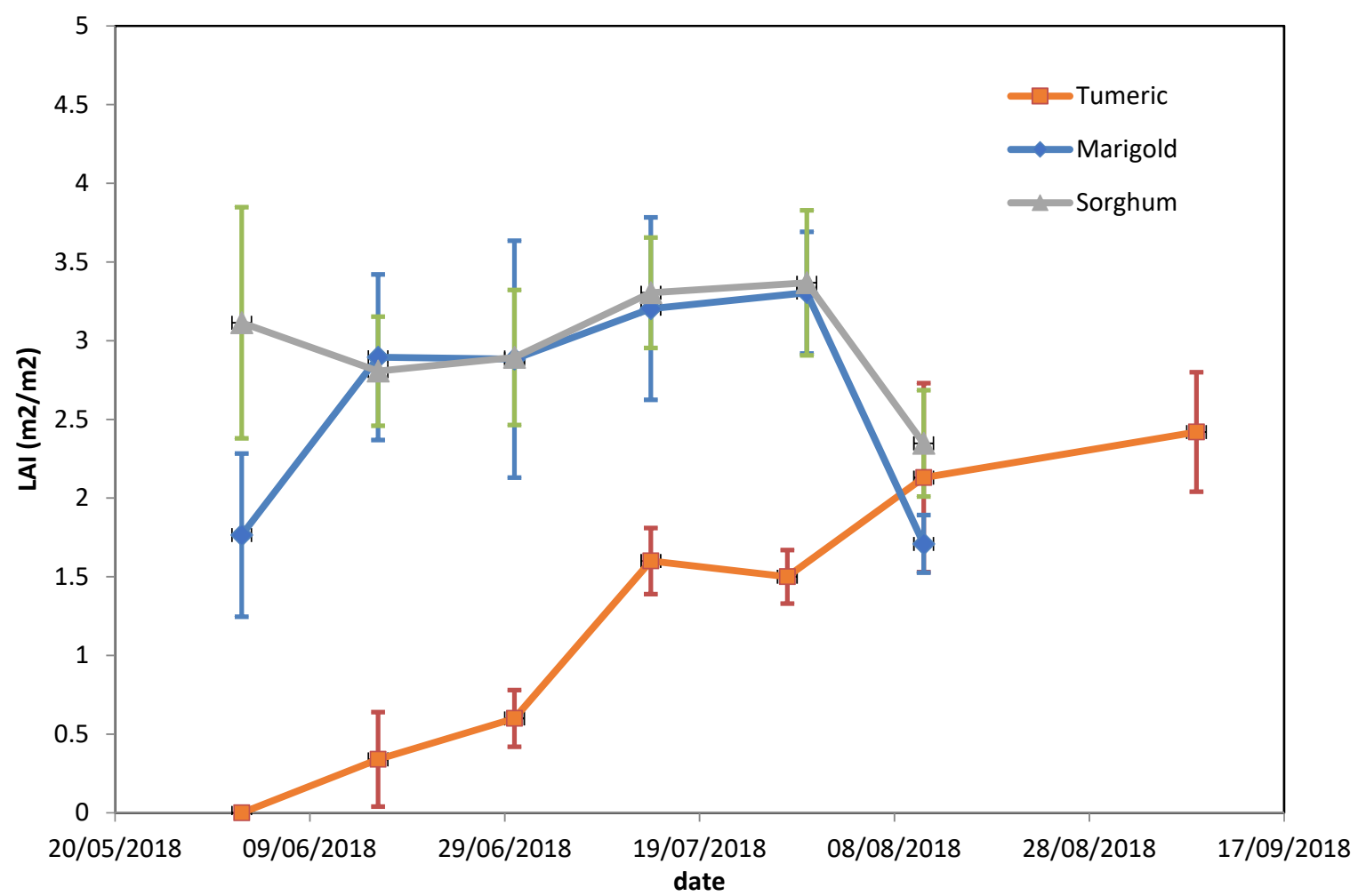

Figure 4. Ground measurements of leaf area index (LAI) in reference fields during the experimental campaigns.

Roughness Measurements

Roughness measurements were made in early June, at the beginning of the ground measurement campaign. These are relevant only for a small number of reference fields, with bare soils or a highly dispersed vegetation cover. The roughness measurements were obtained with a needle profilometer, $150 \mathrm{~cm}$ in length, and a sampling interval of $2 \mathrm{~cm}$ between needles. Six measurements were recorded for each reference field, using three profiles parallel to, and three profiles perpendicular to the direction of tillage. The soil height profiles were considered to be stationary and ergodic. Two statistical parameters were then extracted from the height correlation function (i.e., the soil's RMS height (HRMS)) and its correlation length [71]. The mean values of these two parameters were used to characterize the roughness of each reference field. It is important to note that in these reference fields, no significant directional variations in roughness were observed. In practice, directional variations in the soil's RMS height or correlation length can decrease the accuracy of the modeled relationship between the backscattered radar signals and the mean roughness estimation [72]. The mean values of HRMS in the reference fields ranges between 1.1 and $2.2 \mathrm{~cm}$, corresponding to low to medium values of soil roughness. The soil height correlation length ranges between 4 and $11.3 \mathrm{~cm}$, which is typical for agricultural areas.

\section{Methodology}

\subsection{Backscattering Model}

The aim of the first part of this section is to present five different models used to simulate the PALSAR data in the $\mathrm{HH}$ and HV polarizations over bare soil and vegetation-covered fields. 


\subsubsection{Water Cloud Model (WCM)}

The water cloud model was used to model the radar signal backscattered by covered surfaces. At an incidence angle equal to $\theta$, the backscattering coefficient in this model [35] is given by the following expression:

$$
\sigma^{0}=\sigma_{\text {canopy }}^{0}+\sigma_{\text {canopy }+ \text { soil }}^{0}+\tau^{2} \sigma_{\text {soil }}^{0}
$$

where $\tau^{2}$ is the two-way vegetation transmissivity. The $\sigma_{\text {canopy }}^{0}$ represents scattering produced by the vegetation, whereas $\sigma_{\text {canopy }+ \text { soil }}^{0}$ is related to multiple scattering effects, and $\tau^{2} \sigma_{\text {soil }}^{0}$ represents soil scattering attenuated by the vegetation cover. The second term, which is generally neglected in the case of scattering arising from annual vegetation cover, is used to account for double-bounce scattering. This term is generally neglected in studies dealing with low levels of vegetation cover, even in the L-band [49,53,63], and is known to be particularly low at high incidence angles [10,11].

Equation (1) can thus be simplified to [33]:

$$
\sigma^{0}=\sigma_{\text {canopy }}^{0}+\tau^{2} \sigma_{\text {soil }}^{0}
$$

where $\tau^{2}=\exp (-2 B V 1 \sec \theta)$ and $\sigma_{\text {canopy }}^{0}=A V 2 \cos \theta\left(1-\tau^{2}\right)$ and $V 1$ and $V 2$ are parameters related to the vegetation.

A and B are parameters which depend on the characteristics of the vegetation canopy. This formulation provides a first-order solution for the radiative transfer equation through a weak medium, in which multiple scattering is neglected. The parameters A and B are estimated empirically, using ground-truth measurements and radar signals measured over vegetation covers. The most commonly used vegetation descriptors, which are derived mainly from optical data, include the LAI and NDVI satellite indices, which provide an accurate representation of the influence of vegetation on the total backscattering coefficient in the C-band [20,24].

\subsubsection{Soil Backscattering Models}

In order to retrieve soil moisture, we need to combine the water cloud model with a bare soil backscattering model, to estimate the value of $\sigma_{\text {soil }}^{0}$ defined in Equation (2).

(a) Dubois model

Dubois et al. [32] proposed a semi-empirical model that estimates the co-polarized backscatter coefficient over bare soil, as a function of the dielectric constant, incidence angle, RMS height s, and wavelength. In the present study, we consider the $\mathrm{HH}$ polarization only.

$$
\sigma_{H H}=10^{-2.75}\left(\frac{\cos ^{1.5} \theta}{\sin ^{5} \theta}\right) 10^{0.028 \varepsilon \tan \theta} \lambda^{0.7}(k s \sin \theta)^{1.4}
$$

where $k$ is the wave number, defined as $\frac{2 \pi}{\lambda}, \lambda$ is the wavelength of the radar signal, $\varepsilon$ is the dielectric constant of the soil, and $\theta$ is the incidence angle. The model's domain of validity is defined as: $k s \leq 2.5$; $m v<0.35 \mathrm{~cm}^{3} / \mathrm{cm}^{3}$; and $\theta>30^{\circ}$.

(b) Baghdadi model

Baghdadi et al. [33] proposed a modified version of the Dubois model, which is generalized to include the effects of cross polarization and low incidence angles:

$$
\begin{aligned}
& \sigma_{H H}=10^{-1.287}(\cos \theta)^{1.227} 10^{0.009 \operatorname{cotan}(\theta) m v}(k s)^{0.86 \sin (\theta)} \\
& \sigma_{H V}=10^{-2.325}(\cos \theta)^{-0.01} 10^{0.011 \operatorname{cotan}(\theta) m v}(k s)^{0.44 \sin (\theta)}
\end{aligned}
$$

where $\theta$ is expressed in radians and $m v$ is in vol.\%. 


\section{(c) Oh'92 model}

Oh et al. [31] proposed a semi-empirical model for soil moisture and roughness inversion, which can include the effects of different polarization ratios. In the present study, we consider simulations for the $\mathrm{HH}$ and $\mathrm{HV}$ polarizations.

$$
\begin{gathered}
\sigma H V=0.23 \sqrt{\Gamma 0}(1-\exp (-k s)) \frac{g \cos ^{3} \theta}{\sqrt{P}}(\Gamma h+\Gamma v) \\
\sigma H H=\sqrt{P} g \cos ^{3} \theta(\Gamma h+\Gamma v)
\end{gathered}
$$

where

$$
\begin{gathered}
P=\left(1-\left(\frac{2 \theta}{\pi}\right)^{[1 / 3 \Gamma 0]} \exp (-k s)\right)^{2} \\
g=0.7\left[1-\exp \left(-0.65(k s)^{1.8}\right)\right] \\
\Gamma 0=\left|\frac{1-\sqrt{\varepsilon}}{1+\sqrt{\varepsilon}}\right|^{2} \\
\Gamma h=\left|\frac{\cos \theta-\sqrt{\varepsilon\left(1-\sin ^{2} \theta\right)}}{\cos \theta+\sqrt{\varepsilon\left(1-\sin ^{2} \theta\right)}}\right|^{2} \\
\Gamma h=\left|\frac{\cos \theta-\sqrt{\frac{1}{\varepsilon}\left(1-\sin ^{2} \theta\right)}}{\cos \theta+\sqrt{\frac{1}{\varepsilon}\left(1-\sin ^{2} \theta\right)}}\right|^{2}
\end{gathered}
$$

The Oh model is optimized for bare soils in the following domain of validity: $0.13 \leq k H r m s \leq 6.98$; $4 \leq m v($ vol. $\%) \leq 29.1$; and $10^{\circ} \leq \theta \leq 70^{\circ}$.

(d) IEM model versions

Fung et al. [29] developed the integral equation model (IEM), which made new contributions to theoretical simulations. In recent years, various improvements to this model have been proposed. With the AIEM, Wu et al. [30] introduced a transition function for the reflection coefficient, taking surface roughness and permittivity into account. Baghdadi et al. [73] proposed an empirical calibration of the IEM model, in order to improve the determination of backscattering coefficients on bare agricultural soils. This approach consists in replacing the measured correlation length by a fitting parameter (Lopt) for each data element, thus allowing the IEM simulations to be in very good agreement with the radar measurements. In the L-band, the fitting parameter Lopt was defined for the $H H$ polarization, as a function of the RMS surface height (HRMS) and incidence angle $(\theta)$, as follows:

$$
\operatorname{Lpot}(\text { Hrms, } \theta, H H)=2.6590 \theta^{-1.4493}+3.0484 \text { Hrms } \theta^{-0.8044}
$$

(e) Empirical linear relationship between soil moisture and radar signal

In order to retrieve the volumetric surface soil moisture from a single radar configuration, a linear relationship is generally established between the radar backscattering coefficient $\sigma_{0}$ and $m v$ (vol.\%) alone, in the absence of any knowledge of the soil roughness [26]. This relationship can be expressed as follows:

$$
\sigma_{0}=a m v+b
$$

where the coefficients $a$ and $b$ depend on the incidence angle and polarization of the radar signal, and on the soil roughness. 


\subsection{Statistical Parameters}

In the present study, statistical analyses are applied, using two quality measures: Pearson's correlation, and the RMSE (root mean square error).

Pearson's correlation is defined by:

$$
R=\frac{\sum_{i=1}^{N}\left(x_{i}-\bar{x}\right)\left(y_{i}-\bar{y}\right)}{\sqrt{\sum_{i=1}^{N}\left(x_{i}-\bar{x}\right)^{2}} \sqrt{\sum_{i=1}^{N}\left(y_{i}-\bar{y}\right)^{2}}}
$$

where $x_{i}$ and $y_{i}$ are individual samples taken at points indexed with the variable $i$,

$N$ is the number of samples, $\bar{x}$ is the mean of the samples $x_{i}$, and $\bar{y}$ is the mean of the samples $y_{i}$. RMSE (root mean square error)

$$
R M S E=\sqrt{\frac{1}{N} \sum_{i=1}^{N}\left(P_{i}-O_{i}\right)^{2}}
$$

where $N$ is the number of data samples, $P_{i}$ is the predicted value of sample $i$, and $O_{i}$ is the measured value of sample $i$.

The data are checked to ensure they follow a normal distribution, and for their significance, prior to all analyses. The simulated values of soil moisture (SM) were compared with the in situ measurements, and the validity of each simulation was assessed using the RMSE.

\section{Results and Discussions}

\subsection{Analysis of Radar Signal Sensitivity to Soil Moisture}

In this section, the sensitivity of L-band radar signals to the surface soil moisture is analyzed for $\mathrm{HH}$ and HV radar polarizations, and for different agricultural areas. The results are discussed, firstly for the case of bare soil, and then for the three main crops selected for the present study (i.e., turmeric, marigold, and sorghum).

\subsubsection{Bare Soil}

In the case of bare soils, various studies have shown that the sensitivity of radar signals to soil moisture has a slope $(\mathrm{dB} /(\mathrm{vol} . \%))$, which in general lies between 0.1 and 0.3 [26]. This sensitivity depends mainly on the incidence angle and the SAR polarization used for the observations [26]. Figure 5 shows the variations in HH and HV radar signal strength, as a function of the in situ soil moisture measurements, on the reference plots. The linear regressions shown in this figure correspond to $\mathrm{HH}$ and $\mathrm{HV}$ soil moisture sensitivities equal to $0.21 \mathrm{~dB} /(\mathrm{vol} . \%)$ and $0.20 \mathrm{~dB} /(\mathrm{vol} \%$ ), respectively, for the L-band PALSAR observations. This analysis does not take the influence of soil roughness into account, even though it has an indirect influence on the constant terms determined for the linear regressions ( -15.7 and -24.8 for the $\mathrm{HH}$ and $\mathrm{HV}$ polarizations, respectively). As shown in both theoretical and experimental studies [31,74], the soil roughness has a stronger influence on the backscattered signal strength in the L-band, than at higher frequencies, such as those used in the Cand X-bands. The influence of roughness could also be present in the computed slope, in the case of strong spatio-temporal variations in soil roughness [75]. In the case of the present analysis, there were no significant variations in soil roughness (which was generally low to medium), due to the influence of strong precipitation events. 


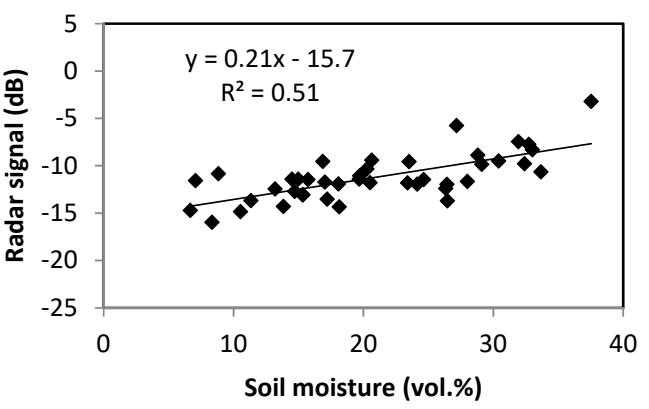

(a)

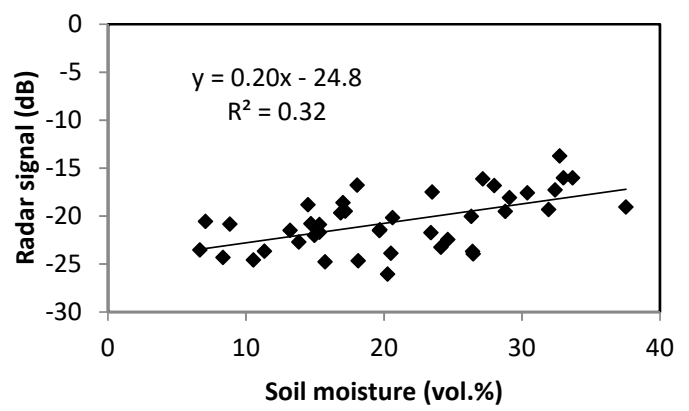

(b)

Figure 5. Phased Array Synthetic Aperture Radar (PALSAR) radar data as a function of soil moisture for bare soils: (a) horizontal-horizontal $(\mathrm{HH})$ polarization, $(\mathbf{b})$ horizontal-vertical (HV) polarization.

\subsubsection{Surfaces with Vegetation Cover}

Three main crops are considered in this analysis, namely turmeric, marigold, and sorghum. In this section, we evaluate the sensitivity of L-band radar signals to soil moisture, in the presence of vegetation cover. In order to clearly distinguish between the influence of vegetation cover and that of soil moisture, we analyze the sensitivity of the radar signals to soil moisture, for two sets of data. For each type of vegetation, two sets of data were thus considered, using the same number of measurements in each case. The first set includes measurements with relatively low values of LAI (less than 2.5), whereas the second set includes all measurements with the strongest values of LAI (LAI $\geq \sim 2.5$ ). For each set, the relationship between soil moisture and radar signal strength was analyzed.

Figure 6 plots the results obtained in the $\mathrm{HH}$ and HV polarizations for turmeric fields, and for the two classes of LAI produced by the aforementioned LAI limit ( 2.5). Firstly, one can note a significant decrease in the sensitivity of radar signals to soil moisture, for the case of fields with a vegetation cover, as compared to fields with bare soil. This outcome is clearly produced by attenuation of the soil signals due to the presence of a vegetation cover, and by the power scattered by the vegetation. The sensitivity is equal to $0.15 \mathrm{~dB} /($ vol.\%) for $\mathrm{LAI}<2.5$, and $0.11 \mathrm{~dB} /(\mathrm{vol} . \%)$ for $\mathrm{LAI}>2.5$. In the case of the HV polarization, the sensitivity is $0.06 \mathrm{~dB} /($ vol.\%) for LAI $<2.5$. This low sensitivity to soil moisture could be explained by the strong, and temporally variable scattering contributed by the vegetation, in the case of low to medium values of LAI (between 0 and 2.5), which in turn reduces the radar signal's sensitivity to soil moisture. As described in the literature, the influence of vegetation on the backscattered radar signals decreases with increasing vegetation biomass. This effect is clearly observed in forests [76], but also for the case of annual agriculture [77]. This behavior explains why noise coming from vegetation effect in radar signal sensitivity to soil moisture could be higher for the low LAI class than for the high LAI class. In fields having a high value of LAI (LAI >2.5), the noise produced by the vegetation cover appears to be relatively small in both polarizations, and the radar signal is mainly sensitive to variations in soil moisture. This outcome indicates that L-band observations can remain sensitive to soil moisture, even in the presence of a high-density vegetation cover (LAI > 2.5).

Figure 7 shows the results derived from observations of the marigold fields. As in the case of the turmeric crops, although the radar signal sensitivity to soil moisture is clearly lower than that observed for bare soil, it remains relatively high, even in the case of densely covered fields. In the $\mathrm{HH}$ polarization, the sensitivities are approximately constant for the two LAI classes, respectively equal to $\sim 0.1 \mathrm{~dB} /(\mathrm{vol} . \%)$ and $\sim 0.11 \mathrm{~dB} /($ vol. $\%)$, thus confirming the limited influence of vegetation cover in terms of attenuation in the L-band. In the HV polarization, the soil moisture sensitivities are equal to $0.15 \mathrm{~dB} /($ vol.\%) and $0.08 \mathrm{~dB} /($ vol.\%), respectively, for the two classes of LAI. The presence of flower blossoms in the case of high values of LAI could explain the corresponding decrease in sensitivity to soil moisture. Theoretical backscattering modeling could provide valuable insight into this behavior. 
Figure 8 plots the results computed for the case of sorghum fields, for which no correlation is observed between soil moisture and radar signal strength, at low-to-medium values of LAI. Conversely, this sensitivity is found to be relatively strong $(0.12 \mathrm{~dB} /(\mathrm{vol} . \%)$ and $0.09 \mathrm{~dB} /(\mathrm{vol} . \%)$ for the $\mathrm{HH}$ and $\mathrm{HV}$ polarizations, respectively) when the LAI $>2.5$. As in the case of the turmeric fields, the growth of low LAI sorghum vegetation, together with strong changes in vegetation biomass (leaves, flowers), could explain the observed absence of sensitivity to soil moisture. Given the small number of data points recorded, it is difficult to draw clear conclusions concerning the specific influence of sorghum LAI and vegetation biomass on soil moisture sensitivity. The results computed for the maximum growth classes (LAI ranging between 2.5 and 5) confirm the strong sensitivity of L-band radar observations to soil moisture, even in the presence of a dense vegetation cover.

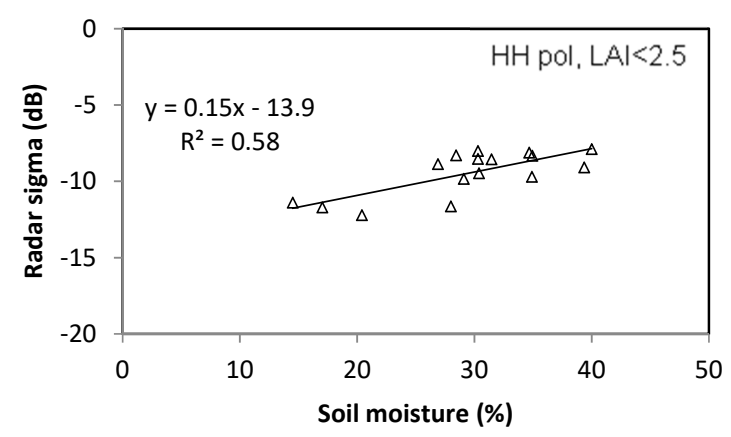

(a)

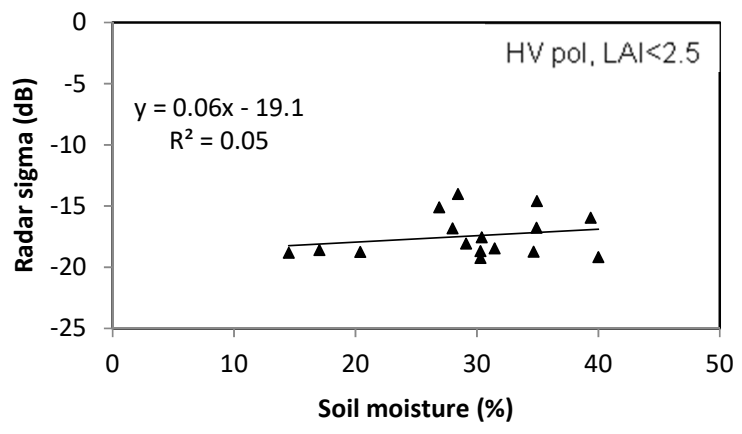

(c)

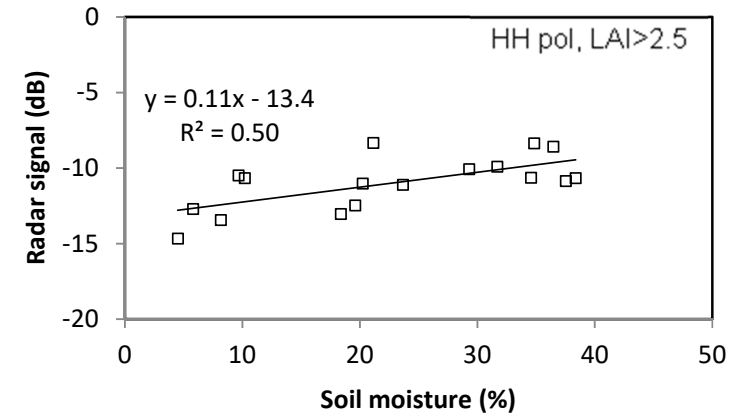

(b)

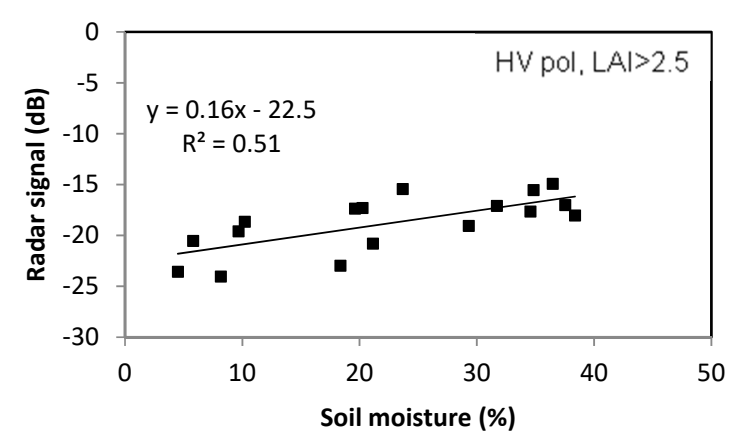

(d)

Figure 6. PALSAR radar data as a function of soil moisture for turmeric cover: (a) HH polarization, $\mathrm{LAI}<2.5$; (b) HH polarization, LAI > 2.5; (c) HV polarization, LAI <2.5; (d) HV polarization LAI > 2.5. 


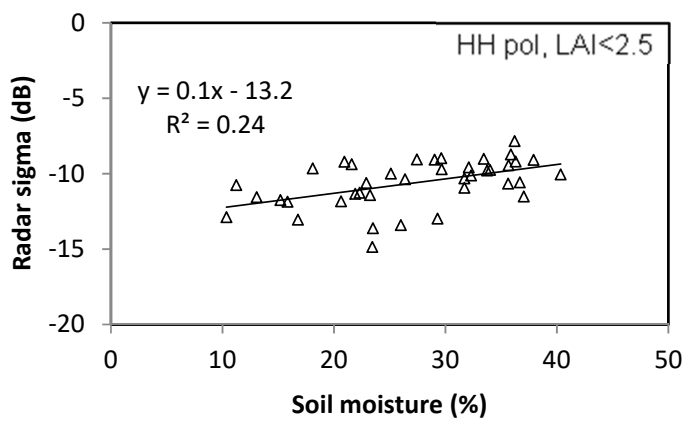

(a)

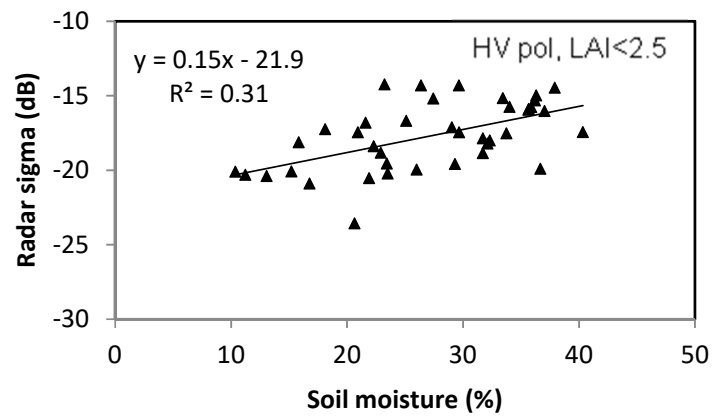

(c)

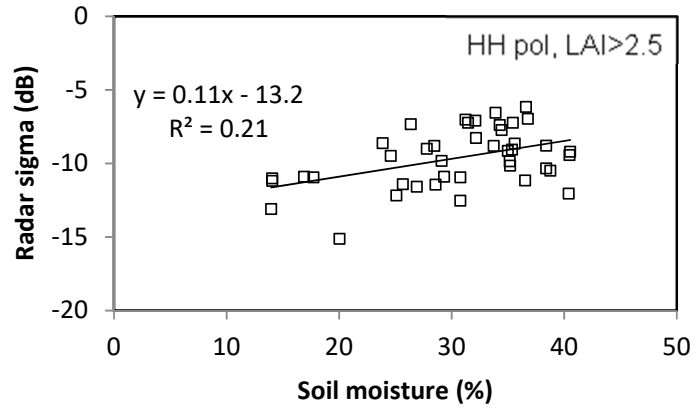

(b)

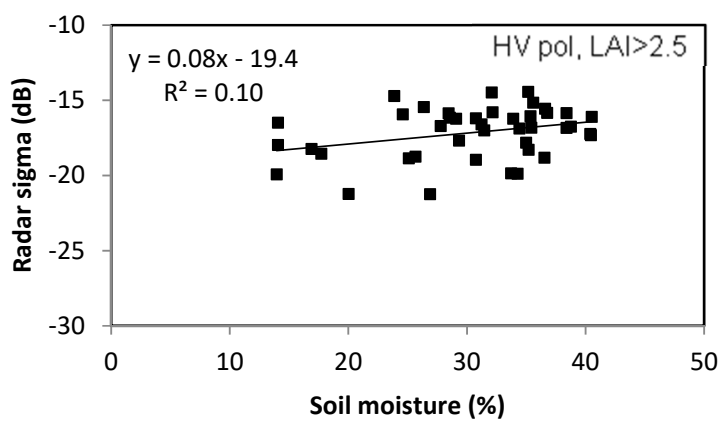

(d)

Figure 7. PALSAR radar data as a function of soil moisture for marigold cover: (a) HH polarization, LAI <2.5; (b) HH polarization, LAI > 2.5; (c) HV polarization, LAI <2.5; (d) HV polarization, LAI > 2.5.

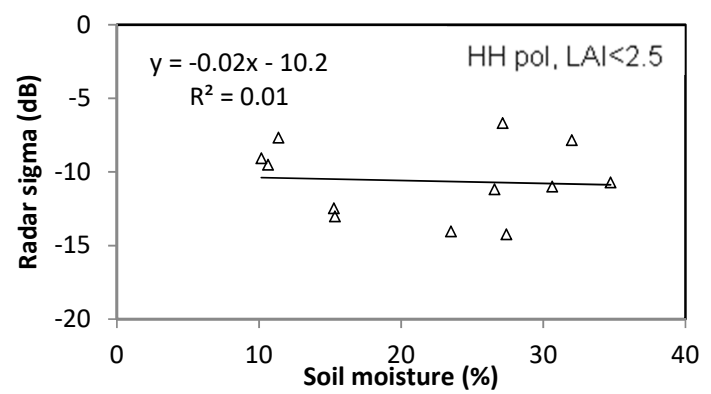

(a)

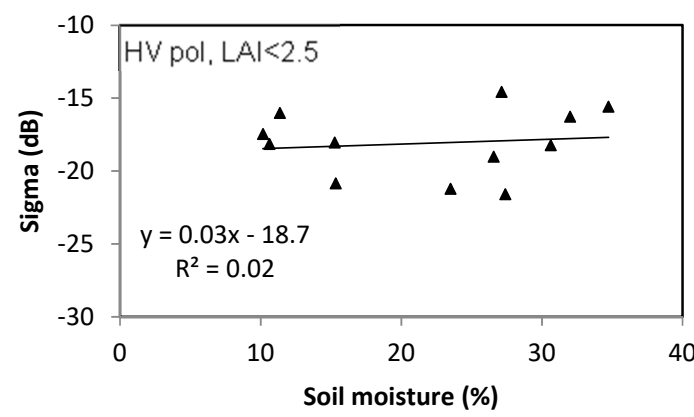

(c)

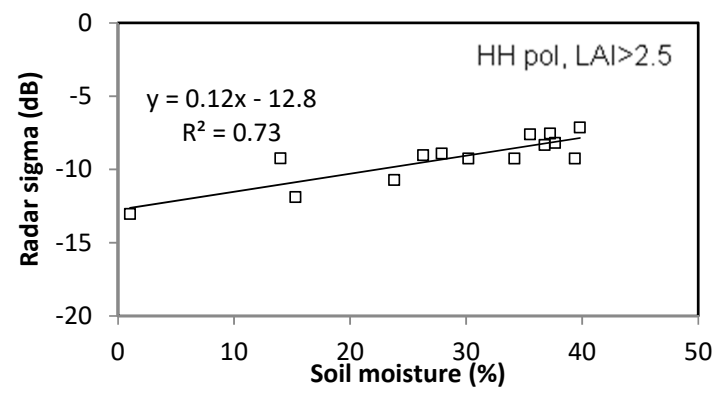

(b)

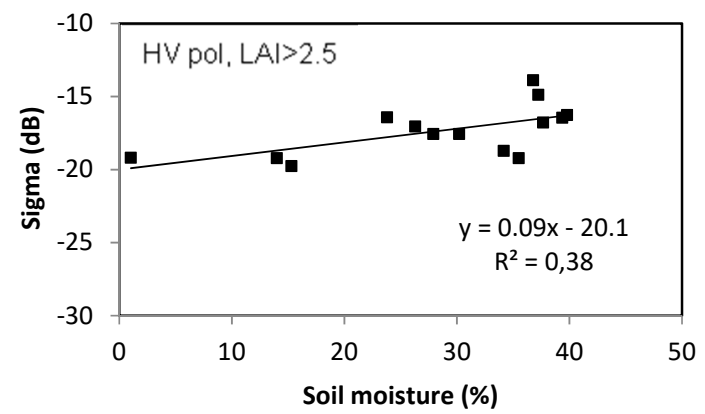

(d)

Figure 8. PALSAR radar data as a function of soil moisture for sorghum cover: (a) HH polarization, LAI <2.5; (b) HH polarization, LAI > 2.5; (c) HV polarization, LAI <2.5; (d) HV polarization, LAI > 2.5. 


\subsection{Backscattering Models}

The aim of this section is to validate the ability of different backscattering models to simulate the behavior of radar signals over bare soils and vegetation-covered surfaces. This approach can then be used to identify models that are suitable for the accurate inversion of radar data.

\subsubsection{Bare Soil Backscattering}

In the case of bare soils, several studies have validated both physical and semi-empirical backscattering models in the L-, C-, and X-bands [78,79]. The validity domains of various models depend on soil roughness and tillage, which can vary from one agricultural area to another. In this section, five models are tested: the AIEM model; the IEM model modified by Baghdadi (IEM_Bagh); the Oh'92 semi-empirical model; the Dubois semi-empirical model; and finally the Baghdadi semi-empirical model, which is a modified version of the Dubois model. The inputs used for these different models are the soil roughness (standard deviation of the height of the soil only, or including its correlation length), the soil moisture converted to a dielectric constant using Hallikainen's empirical model [25], and the radar configurations (frequency, polarization, and incidence angle). It is important to note the relatively small volume of data available for the simulation and evaluation of the proposed models, as just seven plots were available, with roughness measurements carried out at the beginning of the ground campaigns only, in the case of bare soils (June 2018). In the presence of heavy rainfall and irrigation, these measurements are meaningful only at the time when they are recorded. Figure 9 compares the results obtained from the models with the real data. The model with the best performance is found to be the Baghdadi model, with an RMSE equal to 1.2 and $2 \mathrm{~dB}$, for the $\mathrm{HH}$ and $\mathrm{HV}$ polarizations, respectively. The Oh'92 model has the strongest discrepancies with respect to the radar data, with an RMSE equal to 5.4 and $9.4 \mathrm{~dB}$, for the $\mathrm{HH}$ and $\mathrm{HV}$ polarizations, respectively. The AIEM physical model and its modified version have an intermediate accuracy, with an RMSE close to 2-3 dB for the $\mathrm{HH}$ polarization. These results are summarized in Table 1. Despite the small number of data points used for this comparison, the Baghdadi model appears to provide the best simulations of L-band backscattering over bare soil.

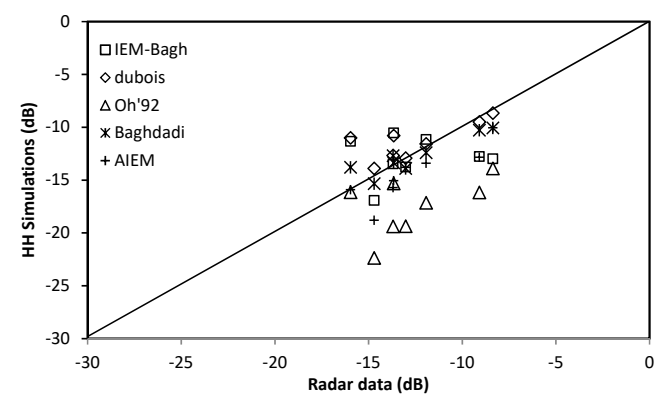

(a)

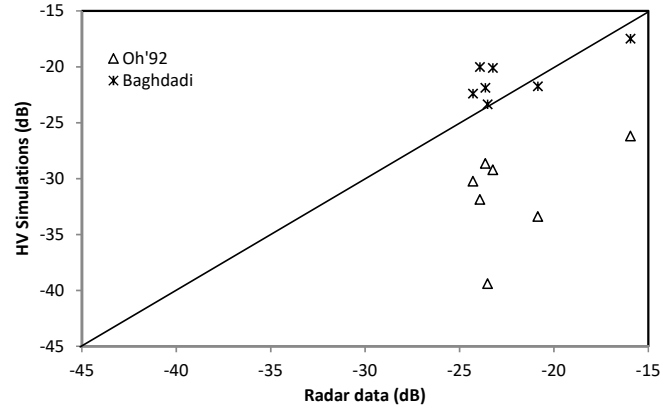

(b)

Figure 9. Comparison between real radar data and simulations using different physical or semi-empirical models: (a) HH polarization; (b) HV polarization.

Table 1. Root mean square (RMS) errors between simulated and real radar data, using five different physical or semi-empirical models.

\begin{tabular}{ccc}
\hline Model & \multicolumn{2}{c}{ RMSE (DB) } \\
\hline & HH pol & HV pol \\
\hline AIEM & 2.2 & - \\
IEM-Bagh & 2.9 & - \\
Oh'92 & 5.4 & 9.4 \\
Dubois & 2.1 & - \\
Baghdadi & 1.2 & 2.1 \\
\hline
\end{tabular}




\subsubsection{Vegetation Covered Soil Backscattering}

For the interpretation of Equation (2) in the present study, we determine the parameters V1 and V2 using the LAI index, and the parameters A and B as a function of the type of canopy. This formulation provides a first-order solution for the radiative transfer equation. In the context of the present study, and in view of the small number of roughness measurements, the simple empirical linear relationships established between the soil moisture and radar signals (described in Section 4.1), are tested with respect to the value of $\sigma_{\text {soil }}$. This approach makes it possible to test the simulation of radar signals, over crops for which larger volumes of L-band data are available. We consider two datasets. The first set ( $50 \%$ of the data) was used to calibrate the parameters A and B, using the least squares method, and the second set ( $50 \%$ of the data) was used for validation of the retrieved model. Figure 10 shows the calibration results obtained for the combined WCM-linear soil backscattering model for three analyzed crops in the HH and HV polarizations. It can be seen that the proposed calibrated model is in good agreement with the observed data. The RMS errors obtained with this model are relatively small, for example: $1.3 \mathrm{~dB}$ and $2.2 \mathrm{~dB}$ for the $\mathrm{HH}$ and $\mathrm{HV}$ polarizations, respectively, in the case of the turmeric crop. Table 2 lists the parameters A and B, as well as the model's statistical performance (RMSE and $\mathrm{R}^{2}$ ), for the three types of crop (turmeric, marigold, and sorghum). It is important to note the limited number of samples considered, in the case of the sorghum crops, for calibration of the WCM (just 14 points). The retrieved values of $A$ and $B$ are thus less robust than in the case of the two other crops: turmeric crops calibrated with a set of 26 points, and marigold crops calibrated with a set of 34 points. For all crops, the RMSE is found to be higher, and the $\mathrm{R}^{2}$ lower, in the HV polarization than in the HH polarization. This is due to approximations used in the water cloud model, neglecting multi-scattering effects, which are known to be stronger in the HV polarization [80].

In the $\mathrm{HH}$ polarization, the parameters A and B have approximately the same order of magnitude for all three crops, thus revealing a certain balance between the influences arising from vegetation attenuation and volume scattering. On the other hand, it can be seen that in the HV polarization, the value of $B$ is very low for turmeric and marigold, and the value of $A$ is very low for sorghum. This could be explained by various limitations in the use of the WCM, due to significant multi-scattering effects, which are not accounted for in the simulations.

Table 2. Water cloud model (WCM) parameters for different crops and polarizations, and RMSE between the calibrated model and the observed data.

\begin{tabular}{cccccc}
\hline Crop & Pol & A & B & RMSE (dB) & $\mathbf{R}^{\mathbf{2}}$ \\
\hline \multirow{2}{*}{ Turmeric } & HH & 0.037 & 0.05 & 1.3 & 0.68 \\
& HV & 5.12 & $6 \times 10^{-5}$ & 2.2 & 0.41 \\
\hline \multirow{2}{*}{ Marigold } & HH & 0.031 & 0.069 & 1.6 & 0.35 \\
& HV & 1.06 & 0.00035 & 1.9 & 0.28 \\
\hline \multirow{2}{*}{ Sorghum } & HH & 0.038 & 0.11 & 0.9 & 0.77 \\
& HV & 0.006 & 0.13 & 1.3 & 0.42 \\
\hline
\end{tabular}




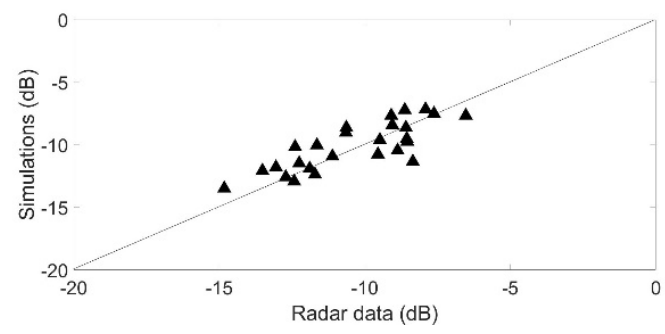

(a)

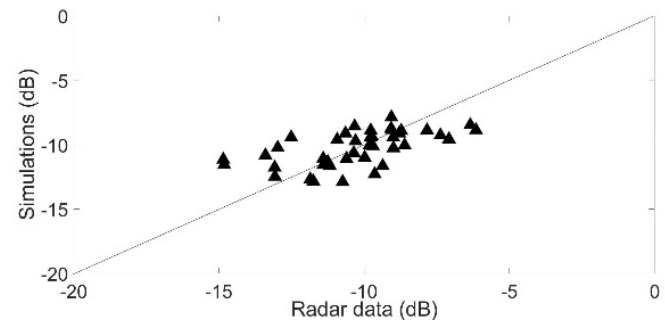

(c)

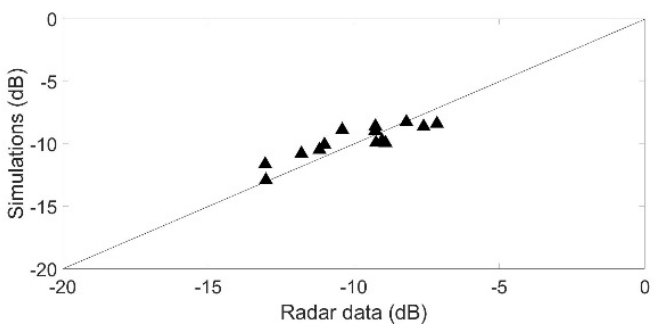

(e)

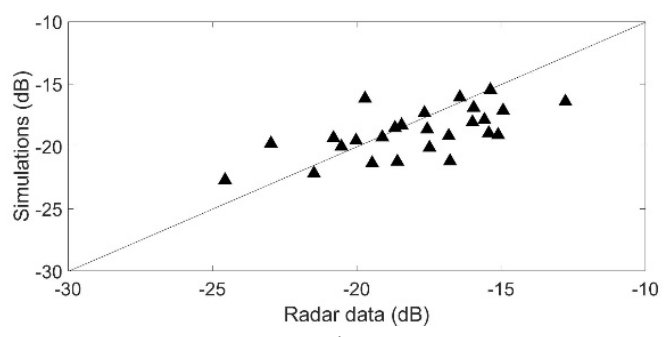

(b)

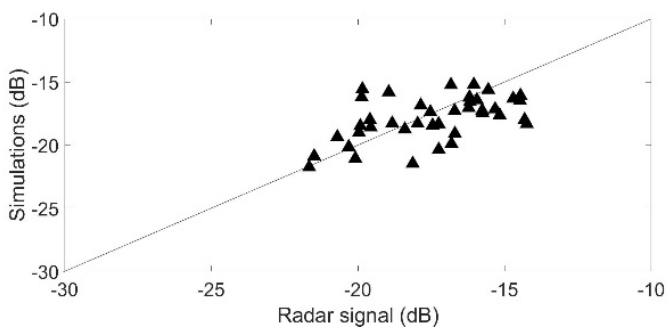

(d)

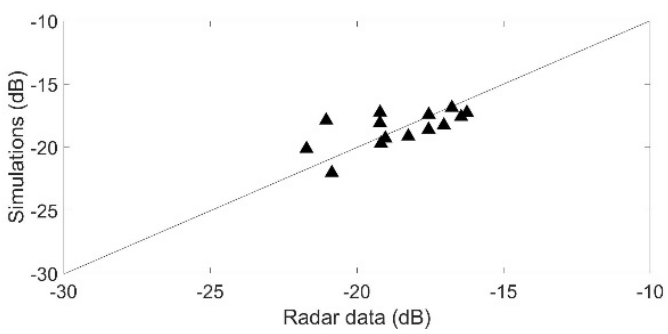

$(\mathbf{f})$

Figure 10. Comparison between calibrated model and radar data for: (a) turmeric, HH polarization, (b) turmeric, HV polarization, (c) marigold, HH polarization, (d) marigold, HV polarization, (e) sorghum, $\mathrm{HH}$ polarization, (f) sorghum, HV polarization.

\subsection{Soil Moisture Estimation}

The results presented in Section 4.1 show that the sensitivity of the radar signal to soil moisture is high, even in the case of crops with a high level of vegetation cover at maximum growth (LAI >2.5). Taking into account the small number of roughness measurements available for this study, we implemented a hybrid approach, combining an empirical model for bare soil backscattering, together with the WCM. The inversion of this model to provide soil moisture values in turmeric and marigold fields is shown in Figure 11. This result was produced using a second set of data (50\% of the data), that were different to the data used for the calibration, with the same number of data points (26 for turmeric and 34 for marigold). Using the known radar signal data, together with the vegetation contribution derived from the LAI measured during the ground campaigns, the soil moisture can be retrieved through direct inversion of the WCM. The in situ moisture measurements and the remotely-sensed estimations are clearly consistent with an RMSE equal to $6.7 \mathrm{vol} . \%$ in the $\mathrm{HH}$ polarization, and $7.9 \mathrm{vol} . \%$ in the HV polarization for turmeric, and an RMSE equal to 8.7 vol.\% in the HH polarization, and 11 vol.\% in the HV polarization for marigold. It can be seen that the accuracy obtained in the HV polarization is lower, probably as a consequence of multi-scattering effects, which are not taken into account in the proposed WCM equations. This leads to a decrease in the accuracy of the soil moisture estimations. The fact that the influence of soil roughness could not be taken into account is likely to have decreased the accuracy of the estimations. Low roughness values lead to the over-estimation of moisture, and vice versa for the case of high roughness conditions.

Table 3 shows the moisture estimations obtained for the three crops. Very high values of RMSE are found for the sorghum crops, corresponding to inaccurate soil moisture estimations. This outcome 
could be explained by the small number of samples (14 samples) used to calibrate the model, and can be expected to limit the robustness of the resulting parameterization.

In the present study, the LAI only was measured. In future studies, it will be of considerable interest to estimate the dry, green biomass and other geometric parameters, which describe the vegetation cover, in order to improve the assessment and understanding of vegetation contributions. Physical backscattering simulations could also be used to study multi-scattering effects in the vegetation cover.

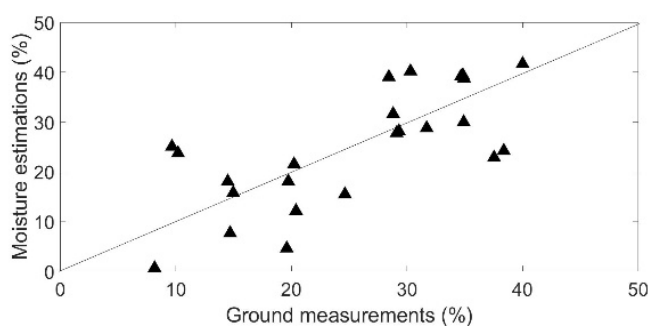

(a)

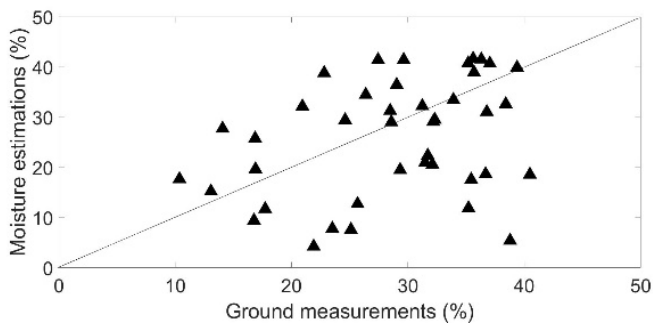

(c)

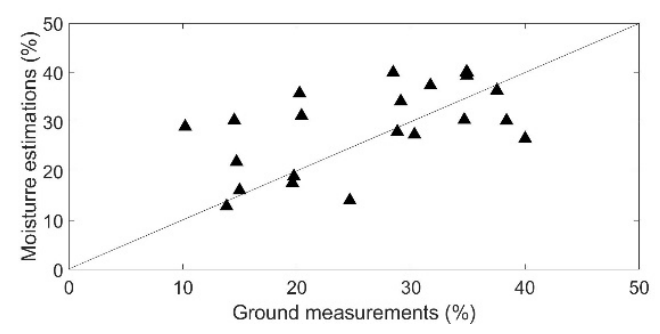

(b)

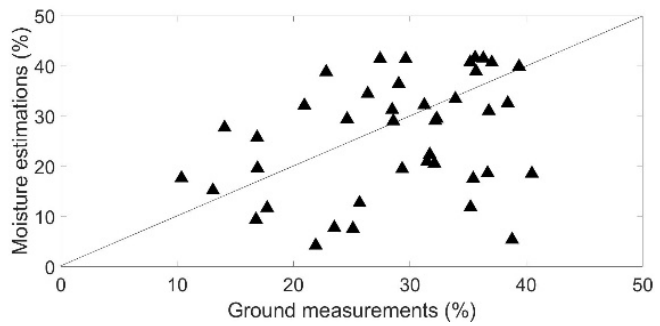

(d)

Figure 11. Comparison between ground measurements and estimated soil moisture values using PALSAR radar data, (a) turmeric, $\mathrm{HH}$ polarization, (b) turmeric, $\mathrm{HV}$ polarization, (c) marigold, $\mathrm{HH}$ polarization, (d) marigold, HV polarization.

Table 3. Accuracy of soil moisture estimations for the three considered crops (turmeric, marigold, and sorghum).

\begin{tabular}{clc}
\hline Crop & Pol & RMSE (vol.\%) \\
\hline \multirow{2}{*}{ Turmeric } & HH & 6.7 \\
& HV & 7.9 \\
\hline \multirow{2}{*}{ Marigold } & HH & 8.7 \\
& HV & 11 \\
\hline \multirow{2}{*}{ Sorghum } & HH & 15.7 \\
& HV & 16.1 \\
\hline
\end{tabular}

\section{Conclusions}

In this study, the potential of PALSAR L-band radar data for the estimation of soil moisture is analyzed on different types of agricultural surfaces, at a tropical, semi-arid site in Berambadi, India. The results are based on a large database acquired over a five-month period (June-October 2018). The PALSAR radar data are compared to field data acquired on 29 test plots, with bare soils and different types of crop (turmeric, marigold, and sorghum).

The sensitivity to soil moisture of radar signals in the $\mathrm{HH}$ and $\mathrm{HV}$ polarizations decrease from bare to covered soils. In the case of covered soils, varying behaviors are observed, which depend on the type of crop. It is important to note that for all types of crop, in the case of dense vegetation, the sensitivity of the signal to moisture remains relatively high (i.e., approximately $0.08-0.15$ for the three types of crop: turmeric, marigold, and sorghum), in both $\mathrm{HH}$ and HV polarizations. The radar signal backscattered over bare soil and fields with a vegetation cover is simulated using different types of electromagnetic models. In the case of bare soil, simulations obtained with the AIEM, IEM-Bagh, 
Oh'92, Dubois, and Baghdadi models show that the latter is best suited to the simulation of real signals, with an RMSE of 1.2 and $2.1 \mathrm{~dB}$, for the $\mathrm{HH}$ and $\mathrm{HV}$ polarizations, respectively, using the tested data. In the case of fields with a vegetation cover, the WCM is calibrated using a soil component simulated with an empirical linear relationship between moisture and radar signal, due to the very small number of roughness measurements available for this study. Moderately accurate soil moisture estimations are obtained for turmeric and marigold fields, using the WCM calibrated with respect to the vegetation (represented by the LAI), with errors equal to 6.7 vol.\% and 7.9 vol.\%, in the HH and HV polarizations, respectively, for turmeric and $8.7 \mathrm{vol} \%$ and $11 \mathrm{vol} \%$, in the $\mathrm{HH}$ and $\mathrm{HV}$ polarizations, respectively, for marigold. In the case of sorghum, the soil moisture estimations made with the WCM are inaccurate. This is probably due to the small number of samples used to calibrate the WCM. The soil moisture estimation errors observed in the HV polarization are higher than in the HH polarization, for the three considered crops. This result could be explained by the fact that multi-scattering effects are not taken into account in the simplified first order radiative transfer equation of the WCM.

In future studies, additional vegetation cover measurements (dry and green biomass and other geometric parameters) should be combined with other physical backscattering models of the vegetation cover, in order to gain an improved understanding of the behavior and interaction of L-band signals with the vegetation. Reliable modeling of multi-scattering effects and a more accurate knowledge of the validity limits of the WCM are also needed.

Author Contributions: M.Z., S.M. and A.A.B. conceived and designed the experiments; S.M. performed the experiments; M.Z., N.B. and S.B. processed the satellite data; M.Z. developed the methodologies; all authors analyzed the results and reviewed the paper; M.Z. wrote the paper.

Acknowledgments: This study was funded by the NISAR and CNRS-PICS MEERENDA projects and the European Space Agency (project: ESA-ESTEC ITT AO/1-8845/16/CT). ALOS PALSAR images were provided by the Japan Aerospace Exploration Agency (pilot project ALOS PI 3023). We extend our warm thanks to the technical teams at the IISc (Avinash, Soundarajan, and Chenju Prince) and CESBIO for their invaluable collaboration and support during the ground-truth measurement campaigns and the data processing operations.

Conflicts of Interest: The authors declare no conflict of interest.

\section{References}

1. Alexandratos, N.; Bruinsma, J. World Agriculture towards 2030/2050: The 2012 Revision; ESA Working Paper No. 12-13; Food and Agriculture Organization of the United Nations: Rome, Italy, 2012.

2. Koster, R.D.; Dirmeyer, P.A.; Guo, Z.; Bonan, G.; Chan, E.; Cox, P.; Gordon, C.T.; Kanae, S.; Kowalczyk, E.; Lawrence, D.; et al. Regions of Strong Coupling Between Soil Moisture and Precipitation. Science 2004, 305, 1138-1140. [CrossRef] [PubMed]

3. Paris Anguela, J.T.; Zribi, M.; Habets, F.; Hasenauer, S.; Loumagne, C. Analysis of surface and root soil moisture dynamics with ERS scatterometer and the hydrometeorological model SAFRAN-ISBA-MODCOU at Grand Morin watershed (France). Hydrol. Earth Syst. Sci. 2008, 5, 1903-1926. [CrossRef]

4. Manfreda, S.; Scanlon, T.M.; Caylor, K.K. On the importance of accurate depiction of infiltration processes on modeled soil moisture and vegetation water stress. Ecohydrology 2009, 3, 155-165.

5. Saux-Picart, S.; Ottlé, C.; Decharme, B.; André, C.; Zribi, M.; Perrier, A.; Coudert, B.; Boulain, N.; Cappelaere, B. Water and Energy budgets simulation over the Niger super site spatially constrained with remote sensing data. J. Hydrol. 2009, 375, 287-295. [CrossRef]

6. Duchemin, B.; Hadria, R.; Erraki, S.; Boulet, G.; Maisongrande, P.; Chehbouni, A.; Escadafal, R.; Ezzahar, J.; Hoedjes, J.C.B.; Kharrou, M.H.; et al. Monitoring Wheat Phenology and Irrigation in Central Morocco: On the Use of Relationships Between Evapotranspiration, Crop Coefficients, Leaf Area Index and Remotely-Sensed Vegetation Indices. Agri. Water Manag. 2006, 79, 1-27. [CrossRef]

7. El Hajj, M.; Baghdadi, N.; Zribi, M.; Belaud, G.; Cheviron, B.; Courault, D.; Charron, F. Soil moisture retrieval over irrigated grassland using X-band SAR data. Remote Sens. Environ. 2016, 176, 202-218. [CrossRef]

8. Francois, $\mathrm{C}$. The potential of directional radiometric temperatures for monitoring soiland leaf temperature and soil moisture status. Remote Sens. Environ. 2002, 80, 122-133. [CrossRef] 
9. Tian, J.; Philpot, W.D. Relationship between surface soil water content, evaporation rate, andwater absorption band depths in SWIR reflectance spectra. Remote Sens. Environ. 2015, 169, 280-289. [CrossRef]

10. Ulaby, F.T.; Moore, R.K.; Fung, A.K. Microwave Remote Sensing Active and Passive; Addison-Wesley: Reading, MA, USA, 1986.

11. Baghdadi, N.; Zribi, M. Microwave Remote Sensing of Land Surfaces, Techniques and Methods; ISTE Press: London, UK, 2016.

12. Paloscia, S.; Macelloni, G.; Santi, E. Soil Moisture Estimates from AMSR-E Brightness Temperatures by Using a Dual-Frequency Algorithm. IEEE Trans. Geosci. Remote Sens. 2006, 44, 3135-3144. [CrossRef]

13. Jackson, T.J.; Cosh, M.H.; Bindlish, R.; Starks, P.J.; Bosch, D.D.; Seyfried, M.; Goodrich, D.C.; Moran, M.S.; $\mathrm{Du}, \mathrm{J}$. Validation of Advanced Microwave Scanning Radiometer Soil Moisture Products. IEEE Geosci. Remote Sens. 2010, 48, 12. [CrossRef]

14. Rodríguez-Fernández, N.J.; Aires, F.; Richaume, F.; Kerr, Y.H.; Prigent, C.; Kolassa, J.; Cabot, F.; Jiménez, C.; Mahmoodi, A.; Drusch, M. Soil moisture retrieval using neural networks: Application to SMOS. IEEE Trans. Geosci. Remote Sens. 2015, 53, 5991-6007. [CrossRef]

15. Al Bitar, A.; Mialon, A.; Kerr, Y.H.; Cabot, F.; Richaume, P.; Jacquette, E.; Quesney, A.; Mahmoodi, A.; Tarot, S.; Parrens, M.; et al. The global SMOS Level 3 daily soil moisture and brightness temperature maps. Earth Sys. Sci. Data 2017, 9, 293-315. [CrossRef]

16. El Hajj, M.; Baghdadi, N.; Zribi, M.; Rodríguez-Fernández, N.; Wigneron, J.P.; Al-Yaari, A.; Al Bitar, A.; Albergel, C.; Calvet, J.C. Evaluation of SMOS, SMAP, ASCAT and Sentinel-1 Soil Moisture Products at Sites in Southwestern France. Remote Sens. 2018, 10, 569. [CrossRef]

17. Moran, M.S.; Peters-Lidard, C.D.; Watts, J.M.; McElroy, S. Estimating soil moisture at the watershed scale with satellite-based radar and land surface models. Can. J. Remote Sen. 2004, 30, 805-826. [CrossRef]

18. Moran, S.; Hymer, D.; Qi, J.; Sano, E. Soil moisture evaluation using multi-temporal synthetic aperture radar (SAR) in semiarid rangeland. Agric. Meteorol. 2000, 105, 69-80. [CrossRef]

19. Paloscia, S.; Pettinato, S.; Santi, E.; Notarnicola, C.; Pasolli, L.; Reppucci, A. Soil moisture mapping using Sentinel-1 images: Algorithm and preliminary validation. Int. J. Remote Sens. 2013, 134, 234-248. [CrossRef]

20. El Hajj, M.; Baghdadi, N.; Zribi, M.; Bazzi, H. Synergic use of Sentinel-1 and Sentinel-2 images for operational soil moisture mapping at high spatial resolution over agricultural areas. Remote Sens. 2017, 9, 1292. [CrossRef]

21. Tomer, S.K.; Al Bitar, A.; Sekhar, M.; Zribi, M.; Bandyopadhyay, S.; Sreelash, K.; Sharma, A.K.; Corgne, S.; Kerr, Y. Retrieval and Multi-Scale Validation of Soil Moisture from Multi-temporal SAR Data in a Tropical Region. Remote Sens. 2015, 7, 8128-8153. [CrossRef]

22. Gao, Q.; Zribi, M.; Baghdadi, N.; Escorihuela, M.J. Synergetic Use of Sentinel-1 and Sentinel-2 Data for Soil Moisture Mapping at $100 \mathrm{~m}$ Resolution. Sensors 2017, 17, 1966. [CrossRef]

23. Bousbih, S.; Zribi, M.; El Hajj, M.; Baghdadi, N.; Lili-Chabaane, Z.; Gao, Q.; Fanise, P. Soil moisture and irrigation mapping in a semi-arid region based on Sentinel-1 and Sentinel-2 synergy. Remote Sens. 2018, 10, 1953. [CrossRef]

24. Zribi, M.; Gorrab, A.; Baghdadi, N.; Lili-Chabaane, Z.; Mougenot, B. Influence of radar frequency on the relationship between bare surface soil moisture vertical profile and radar backscatter. IEEE Trans. Geosci. Remote Sens. Lett. 2014, 11, 848-852. [CrossRef]

25. Hallikainen, M.T.; Ulaby, F.T.; Dobson, M.C.; El-Rayes, M.A.; Wu, L.K. Microwave dielectric behavior of wet soil-part I: Empirical models and experimental observations. IEEE Trans. Geosci. Remote Sens. 1985, 23, $25-46$. [CrossRef]

26. Zribi, M.; Baghdadi, N. Chapter: Analysis of soil properties using high resolution radar remote sensing, Soils and Sediments as Archives of Environmental Change. In Geoarchaeology and Landscape Change in the Subtropics and Tropics; Lucke, B., Bäumler, R., Schmidt, M., Eds.; Fränkische Geographische Gesellschaft: Erlangen, Germany, 2015.

27. Fieuzal, R.; Duchemin, B.; Jarlan, L.; Zribi, M.; Baup, F.; Merlin, O.; Dedieu, G.; Garatuza-Payan, J.; Watt, C.; Chehbouni, A. Combined use of optical and radar satellite data for the monitoring of irrigation and soil moisture of wheat crops. Hydrol. Earth Syst. Sci. 2011, 15, 1117-1129. [CrossRef]

28. Aubert, M.; Baghdadi, N.; Zribi, M.; Douaoui, A.; Loumagne, C.; Baup, F.; El Hajj, M.; Garrigues, S. Analysis of TerraSAR-X data sensitivity to bare soil moisture, roughness, composition and soil crust. Remote Sens. Environ. 2011, 115, 1801-1810. [CrossRef] 
29. Fung, A.K.; Li, Z.; Chen, K.S. Backscattering from a randomly rough dielectric surface. IEEE Trans. Geosci. Remote Sens. 1992, 30, 356-369. [CrossRef]

30. Wu, T.D.; Chen, K.S.; Shi, J.; Fung, A.K. A transition model for the reflection coefficient in surface scattering. IEEE Trans. Geosci. Remote Sens. 2001, 39, 2040-2050.

31. Oh, Y.; Sarabandi, K.; Ulaby, F.T. An empirical model and an inversion technique for radar scattering from bare soil surfaces. IEEE Trans. Geosci. Remote Sens. 1992, 30, 370-382. [CrossRef]

32. Dubois, P.C.; Van Zyl, J.; Engman, T. Measuring soil moisture with imaging radars. IEEE Trans. Geosci. Remote Sens. 1995, 33, 915-926. [CrossRef]

33. Baghdadi, N.; Choker, M.; Zribi, M.; El-hajj, M.; Paloscia, S.; Verhoest, N.; Lievens, H.; Baup, F.; Mattia, F. A new empirical model for radar scattering from bare soil surfaces. Remote Sens. 2016, 8, 920. [CrossRef]

34. Karam, M.A.; Fung, A.K.; Chauhan, N.S. A microwave scattering model for layered vegetation. IEEE Trans. Geosci. Remote Sens. 1992, 30, 767-784. [CrossRef]

35. Attema, E.P.W.; Ulaby, F.T. Vegetation modeled as a water cloud. Radio Sci. 1978, 13, 357-364. [CrossRef]

36. Bindlish, R.; Barros, A.P. Parameterization of vegetation backscatter in radar-based, soil moisture estimation. Remote Sens. Environ. 2001, 76, 130-137. [CrossRef]

37. Baghdadi, N.; El Hajj, M.; Zribi, M.; Bousbih, S. Calibration of the Water Cloud Model at C-Band for Winter Crop Fields and Grasslands. Remote Sens. 2017, 9, 969. [CrossRef]

38. Prévot, L.; Champion, I.; Guyot, G. Estimating surface soil moisture and leaf area index of a wheat canopy using a dual-frequency (C and X bands) scatterometer. Int. J. Remote Sens. 1993, 46, 331-339. [CrossRef]

39. Zribi, M.; Saux-Picart, S.; André, C.; Descroix, L.; Ottlé, O.; Kallel, A. Soil moisture mapping based on ARSAR/ENVISAT radar data over a sahelian site. Int. J. Remote Sens. 2007, 28, 3547-3565. [CrossRef]

40. Balenzano, A.; Mattia, F.; Satalino, G.; Davidson, M.W.J. Dense temporal series of C-and L-band SAR data for soil moisture retrieval over agricultural crops. IEEE J. Sel. Top. Appl. Earth Obs. Remote Sens. 2011, 4, 439-450. [CrossRef]

41. Bauer-Marschallinger, B.; Freeman, V.; Cao, S.; Paulik, C.; Schaufler, S.; Stachl, T.; Modanesi, S.; Massari, C.; Ciabatta, L.; Brocca, L.; et al. Toward Global Soil Moisture Monitoring with Sentinel-1: Harnessing Assets and Overcoming Obstacles. IEEE Trans. Geosci. Remote Sens. 2019, 57, 520-539. [CrossRef]

42. Yamaguchi, Y.; Boerner, W.M.; Yang, J.; Sato, R.; Yamada, H. ALOS-PALSAR Quad. Pol. images and their applications. In Proceedings of the 2nd Asian-Pacific Conference on Synthetic Aperture Radar, Xi'an, China, 26-30 October 2009.

43. Yokota, Y.; Okada, Y.; Nakamura, S.; Iribe, K.; Tsuji, M.; Hariu, K.; Kankaku, Y.; Suzuki, S.; Shimada, M. PALSAR-2 initial mission check. In Proceedings of the 2014 IEEE Geoscience and Remote Sensing Symposium, Quebec, QC, Canada, 13-18 July 2014.

44. Kim, S.B.; Van Zyl, J.J.; Jhonson, J.T.; Moghaddam, M.; Tsang, L.; Collindar, A.; Dunbar, R.S.; Jackson, T.J.; Jaruwatanadilok, S.; West, R.; et al. Surface soil moisture retrieval using the L-band Synthetic Aperture Radar onboard the soil moisture active-passive satellite and evaluation at core validation sites. IEEE Trans. Geosci. Remote Sens. 2017, 55, 1897-1913. [CrossRef]

45. Ferro-Famil, L.; Potier, E. Synthetic Aperture Radar Imaging. In Microwave Remote Sensing of Land Surfaces, Techniques and Methods; ISTE Press: London, UK, 2016.

46. Whelen, T.; Siqueira, P. Use of time series L-band UAVSAR data for the classification of agricultural fields in the San Joaquin Valley. Remote Sens. Environ. 2017, 193, 216-224. [CrossRef]

47. Park, S.; Im, J.; Parek, S.; Yoo, C.; Han, H.; Rhee, J. Classification and mapping of paddy rice by combining Landsat and SAR time series data. Remote Sens. 2018, 10, 447. [CrossRef]

48. Symenonakis, E.; Higginbottom, T.P.; Petroulaki, K.; Rabe, A. Optimisation of Savannah land cover characterization with optical and SAR data. Remote Sens. 2018, 10, 499. [CrossRef]

49. Hosseini, M.; McNairn, H.; Merzouki, A.; Pacheco, A. Estimation of leaf area index (LAI) in corn and soybeans using multi-polarization C- and L-band radar data. Remote Sens. Environ. 2015, 170, 77-89. [CrossRef]

50. Joseph, A.T.; Van Der Velde, R.; O'neill, P.E.; Lang, R.; Gish, T. Effects of corn on C-and L-band radar backscatter: A correction method for soil moisture retrieval. Remote Sens. Environ. 2010, 114, 2417-2430. [CrossRef]

51. Jagdhuber, T.; Hajnsek, I.; Bronstert, A.; Papathanassiou, K.P. Soil moisture estimation under low vegetation cover using a multi-angular polarimetric decomposition. IEEE Trans. Geosci. Remote Sens. 2013, 51, 2201-2215. [CrossRef] 
52. He, L.; Panciera, R.; Tanase, M.A.; Walker, J.P.; Qin, Q. Soil moisture retrieval in agricultural fields using adaptive model-based polarimetric decomposition of SAR data. IEEE Trans. Geosci. Remote Sens. 2016, 54, 4445-4460. [CrossRef]

53. Liu, P.W.; Judge, J.; DeRoo, R.D.; England, A.W.; Bongiovanni, T.; Luke, A. Dominant backscattering mechanisms at L-band during dynamic soil moisture conditions for sandy soils. Remote Sens. Environ. 2016, 178, 104-112. [CrossRef]

54. Barber, M.; Lopez-Martinez, C.; Grings, F. Crop scattering analysis of L-band POLSAR data for vegetation and soil monitoring. In Proceedings of the International Geoscience and Remote Sensing Symposium, Beijing, China, 10-15 July 2016.

55. Martino, G.G.; Iodice, A.; Natale, A.; Riccio, D. Polarimetric two-scale two-componenet model for the retrieval of soil moisture under moderate vegetation via L-band SAR data. IEEE Trans. Geosci. Remote Sens. 2016, 54, 2470-2491. [CrossRef]

56. Jagdhuber, T.; Hajnsek, I.; Papathanassiou, K.P. An iterative generalized hybrid decomposition for soil moisture retrieval under vegetation cover using fullty polarimetric SAR. IEEE J. Sel. Top. Appl. Earth Obs. Remote Sens. 2015, 8, 3911-3922. [CrossRef]

57. Hajnsek, I.; Jagdhuber, T.; Schon, H.; Papathanassiou, K.P. Potenial of estimating soil moisture under vegetation cover by means of PolSAR. IEEE Trans. Geosci. Remote Sens. 2009, 47, 442-454. [CrossRef]

58. Kasischke, E.S.; Tanase, M.A.; Bourgeau-Chavez, L.L.; Borr, M. Soil moisture limitations on monitoring boreal forest regrowth using spaceborne L-band SAR data. Remote Sens. Environ. 2011, 115, 227-232.

59. Wang, H.; Magagi, R.; Goita, K. Comparison of different polarimetric decompositions for soil moisture retrieval over vegetation covered agricultural area. Remote Sens. Environ. 2017, 199, 120-136. [CrossRef]

60. Bruscantini, C.A.; Konings, A.G.; Narvekar, P.S.; McColl, K.A.; Entekhabi, D.; Grins, F.M.; Karszenbaum, H. L-band radar soil moisture retrieval without ancillary information. IEEE J. Sel. Top. Appl. Earth Obs. Remote Sens. 2015, 8, 5526-5540. [CrossRef]

61. Kim, S.; Arii, M.; Jackson, T.J. Modeling L-band synthetic aperture radar observations through dielectric changes in soil moisture and vegetation over shrublands. IEEE J. Sel. Top. Appl. Earth Obs. Remote Sens. 2017, 10, 4753-4762. [CrossRef]

62. Sun, R.; Shi, J.; Jackson, T.; Chen, K.; Oh, Y. Improvement of bare surface soil moisture estimation with L-band dual-polarization radar. In Proceedings of the International Geoscience and Remote Sensing Symposium, Cape Town, South Africa, 12-17 July 2009.

63. Liu, C.; Shi, J. Estimation of vegetation parameters of water cloud model for global soil moisture retrieval using time-series L-band Aquarius observations. IEEE J. Sel. Top. Appl. Earth Obs. Remote Sens. 2016, 9, 5621-5633. [CrossRef]

64. Rosen, P.; Hensley, S.; Shaffer, S.; Edelstein, W.; Kim, Y.; Kumar, R.; Misra, T.; Bhan, R.; Sagi, R. The NASA-ISRO SAR (NISAR) mission dual-band radar instrument preliminary design. In Proceedings of the 2017 IEEE International Geoscience and Remote Sensing Symposium (IGARSS), Fort Worth, TX, USA, 23-28 July 2017.

65. Kotter, M.; Grieser, J.; BECK, C.; Rudolf, B.; Rubel, F. World Map of the Köppen-Geiger climate classification updated. Meteorol. Z. 2006, 15, 259-263. [CrossRef]

66. Multiscale Tropical Catchments (M-Tropics). Available online: https://mtropics.obs-mip.fr/ (accessed on 8 May 2019).

67. Assimilation of Multi-Satellite Data at Berambadi Watershed for Hydrology and land Surface Experiment. Available online: www.ambhas.com (accessed on 8 May 2019).

68. Muddu, S.; Javeed, Y.; Bandyopadhyay, S.; Mangiarotti, S.; Mazzega, P. Groundwater management practices and emerging challenges: Lessions from a case study in the Kamataka state of south India. In Groundwater Management Practices; Findikakis, A.N., Sato, K., Eds.; CRC Press: London, UK, 2011; p. 436.

69. Next ESA SAR Toolbox. Available online: https://earth.esa.int/web/nest/home/ (accessed on 8 May 2019).

70. Veloso, A.; Mermoz, S.; Bouvet, A.; Le Toan, T.; Planells, M.; Dejoux, J.F.; Ceschia, E. Understanding the temporal behavior of crops using Sentinel-1 and Sentinel-2-like data for agricultural applications. Remote Sens. Environ. 2017, 199, 415-426.

71. Zribi, M.; Baghdadi, N.; Holah, N.; Fafin, O.; Guérin, C. Evaluation of a rough soil surface description with ASAR-ENVISAT Radar Data. Remote Sens. Environ. 2005, 95, 67-76. [CrossRef]

72. Zribi, M.; Ciarletti, V.; Taconet, O.; Vidal-Madjar, D. Effect of rows structure on radar microwave measurements over soil surface. Int. J. Remote Sens. 2002, 23, 5211-5224. [CrossRef] 
73. Baghdadi, N.; Zribi, M.; Paloscia, S.; Verhoest, N.; Lievens, H.; Baup, F.; Mattia, F. Semi-Empirical Calibration of the Integral Equation Model for Co-Polarized L-Band Backscattering. Remote Sens. 2015, 7, 13626-13640. [CrossRef]

74. Zribi, M.; Gorrab, A.; Baghdadi, N. A new soil roughness parameter for the modelling of radar backscattering over bare soil. Remote Sens. Environ. 2014, 152, 62-73. [CrossRef]

75. Zribi, M.; Baghdadi, N.; Holah, N.; Fafin, O. New methodology for soil surface moisture estimation and its application to ENVISAT-ASAR multi-incidence data inversion. Remote Sens. Environ. 2005, 96, 485-496. [CrossRef]

76. Baghdadi, N.; le Maire, G.; Bailly, J.S.; Osé, K.; Nouvellon, Y.; Zribi, M.; Lemos, C.; Hakamada, R. Evaluation of ALOS/PALSAR L-band data for the estimation of Eucalyptus plantations aboveground biomass in Brazil. IEEE J. Sel. Top. Appl. Earth Obs. Remote Sens. 2015, 8, 3802-3811. [CrossRef]

77. McNairn, H.; Jiao, X.; Pacheco, A.; Sinha, A.; Tan, W.; Li, Y. Estimating canola phenology using synthetic aperture radar. Remote Sens. Environ. 2018, 219, 196-205. [CrossRef]

78. Shi, J.; Wang, J.; Hsu, A.Y.; O’Neill, P.E.; Engman, E.T. Estimation of bare surface soil moisture and surface roughness parameter using L-band SAR image data. IEEE Trans. Geosci. Remote Sens. 1997, 35, 1254-1266.

79. Choker, M.; Baghdadi, N.; Zribi, M.; El Hajj, M.; Paloscia, S.; Verhoest, N.E.C.; Lievens, H.; Mattia, F. Evaluation of the Oh, Dubois and IEM backscatter models using a large dataset of SAR data and experimental soil measurements. Water 2017, 9, 38. [CrossRef]

80. Fung, A.K. Microwave Scattering and Emission Models and Their Applications; Artech House: Norwood, UK, 1994.

(C) 2019 by the authors. Licensee MDPI, Basel, Switzerland. This article is an open access article distributed under the terms and conditions of the Creative Commons Attribution (CC BY) license (http://creativecommons.org/licenses/by/4.0/). 